\title{
The Influence of Hybrid Renewable Energy Source Plant Composition on Transmission System Stability
}

DOI:

10.1109/ISGT-Europe47291.2020.9248805

Link to publication record in Manchester Research Explorer

\section{Citation for published version (APA):}

Radovanovic, A., Naranjo Plaza, J., Li, X., \& Milanovic, J. V. (2020). The Influence of Hybrid Renewable Energy Source Plant Composition on Transmission System Stability. 584-588. Paper presented at 2020 IEEE PES Innovative Smart Grid Technologies Conference Europe (ISGT-Europe), The Hague, Netherlands. https://doi.org/10.1109/ISGT-Europe47291.2020.9248805

\section{Citing this paper}

Please note that where the full-text provided on Manchester Research Explorer is the Author Accepted Manuscript or Proof version this may differ from the final Published version. If citing, it is advised that you check and use the publisher's definitive version.

\section{General rights}

Copyright and moral rights for the publications made accessible in the Research Explorer are retained by the authors and/or other copyright owners and it is a condition of accessing publications that users recognise and abide by the legal requirements associated with these rights.

\section{Takedown policy}

If you believe that this document breaches copyright please refer to the University of Manchester's Takedown Procedures [http://man.ac.uk/04Y6Bo] or contact uml.scholarlycommunications@manchester.ac.uk providing relevant details, so we can investigate your claim.

\section{OPEN ACCESS}




\section{The Influence of Hybrid Renewable Energy Source Plant Composition on Transmission System Stability}

\author{
Ana Radovanović, Student Member IEEE \\ Department of Electrical and Electronic Engineering \\ The University of Manchester \\ Manchester, UK \\ ana.radovanovic@manchester.ac.uk \\ Xindong $\mathrm{Li}$ \\ Department of Electrical and Electronic Engineering \\ The University of Manchester \\ Manchester, UK \\ xindong.li@student.manchester.ac.uk
}

\author{
Joey Naranjo Plaza \\ Department of Electrical and Electronic Engineering \\ The University of Manchester \\ Manchester, UK \\ joey.naranjoplaza@student.manchester.ac.uk \\ Jovica V. Milanović, Fellow IEEE \\ Department of Electrical and Electronic Engineering \\ The University of Manchester \\ Manchester, UK \\ milanovic@manchester.ac.uk
}

\begin{abstract}
Hybrid power plants consisting of renewable generation and storage technologies have been seen as a solution for providing stable power output from renewable energy sources. Given the installation capacity of renewable generation and storage units, their impact on power system operation can no longer be neglected. The paper analyzes the influence of a hybrid renewable energy source plant on small disturbance, transient and voltage transmission system stability on the basis of a representative set of power production profiles of the plant. The patterns in the behavior of the whole plant in the considered system stability studies are identified, which is a first step in developing dynamic equivalent models of the hybrid power plant for those types of system stability.
\end{abstract}

Keywords-hybrid renewable energy source plant, small signal stability, transient stability, voltage stability

\section{INTRODUCTION}

Over the past several decades renewable energy sources (RESs) have attracted attention due to the growing concerns for environmental protection and sustainable development. However, the increase in the installation capacity of RES and storage technologies has caused significant alterations in electric power systems' structure and operation. These new sources are usually connected to distribution network voltage levels and characterized by small installation capacity and power electronic interface, which makes them considerably different from conventional power plants [1], [2]. Reversible power flows, lower mechanical inertia levels, changes in the profiles of line losses, voltage drops along lines and short-circuit fault currents are only some of the consequences of connecting RES and storage units to power systems [3], [4]. Therefore, the influence of RES and storage technologies on the overall power system performance can no longer be neglected.

As stochastic production and weather dependence are among the main issues associated with RES integration, hybrid power plants consisting of a mix of generation and storage technologies have been recognized as potential solutions for ensuring more flexible and secure power output. Most of the papers in the area of hybrid energy systems are focused on defining the optimal plant configuration taking into account annual costs and reliability of power supply [5].
Geographical spread, a large number of RES and storage units and the diversity of technologies have made it difficult to analyze their aggregate contribution to various aspects of power system operation. The research on the influence of individual technologies on power system performance has been well established, but few studies about the impact of hybrid power plants on power system dynamics have been reported [6]. Modelling each of the units in RES and storage plants individually in system stability studies is becoming impractical due to high computational complexity and lack of detailed dynamic data. As a result, equivalent dynamic representation of RES and storage plants is gaining popularity [7]. Dynamic equivalents can provide quick assessment of power system stability, with satisfactory accuracy of the results [7].

The paper investigates the aggregate contribution of several non-dispatchable and dispatchable renewable generation and storage technologies to transmission system operation. The considered technologies are integrated into a hybrid renewable energy source (HRES) plant with a single point of common coupling (PCC). The assessment of the influence of the HRES plant on transmission network stability is based on a set of representative HRES plant compositions. The focus of system stability studies is on angular (small and large disturbance) and voltage stability. For each of the analyzed types of system stability, power production profiles that result in similar behavior of the HRES plant at the PCC are identified.

\section{Methodology}

The main objective of the study is to analyze the impact of different HRES plant compositions on small signal, transient and voltage stability of a transmission system. The analysis represents an initial step towards developing equivalent dynamic models of the whole HRES plant suitable for the considered types of system stability studies.

The flow chart of the methodology is illustrated in Fig. 1. Firstly, the HRES plant structure is chosen and HRES plant model is developed in DIgSILENT PowerFactory software (blocks (1) and (2) in Fig. 1, respectively). Following this, a set of case studies (CSs) is defined in order to investigate the impact of different HRES plant operating conditions on 
transmission system stability (block (3) in Fig. 1). The total active power output of the HRES plant is the same in all CSs, while the contribution of individual technologies to the total plant production is varied. Prior to carrying out simulations, the convergence of load flow calculation is checked for each CS (block (5) in Fig. 1).

Small signal stability analysis involves computing all system eigenvalues and identifying system stability (block (7) in Fig. 1). The classical QR transformation method is used for the calculation of the eigenvalues [8]. The contribution of different plant compositions to small signal stability of transmission network is assessed on the basis of parameters of electromechanical oscillation modes. Only electromechanical modes are taken into consideration in further analysis as these modes are the ones that persist longest and thus determine the overall system dynamic behavior [8].

The analysis of the influence of HRES plant compositions on transient system stability requires conducting electromechanical simulations (block (9) in Fig. 1). Three phase self-clearing fault is selected as an external system disturbance as it usually results in the most severe operating conditions in power system (block (6) in Fig. 1). The fault location and duration are the same in all CSs. Active and reactive power dynamic responses at the $\mathrm{PCC}$ are recorded for the analyzed HRES plant operating points.

Voltage stability studies are performed by computing P-V curves at the selected buses (block (8) in Fig. 1). Voltage stability limit is determined by increasing the selected system loads gradually until the load flow calculation stops converging. The critical load level (the load level at which voltage collapse occurs) and the voltage of the bus that collapses first are used to analyze the impact of the HRES plant on voltage stability.

\section{TEST SYSTEM}

As already mentioned in Section II, the test system used in this paper (presented in Fig. 2) is modelled in DIgSILENT PowerFactory software package [9]. The HRES plant consists of 7 technologies: 2 dispatchable renewable generation plants (a pumped-storage hydro and biomass power plant), 2 non-dispatchable renewable generation plants (a photovoltaic (PV) plant and wind farm (WF)) and 3 storage systems (a battery (BESS), flywheel (FESS) and compressed air (CAES) energy storage system). All the considered technologies are connected to a common $110 \mathrm{kV}$ bus, i.e., the PCC (Bus 18 in Fig. 2). The distance of the analyzed technologies from the PCC is equal to $0.5 \mathrm{~km}$. The HRES plant is connected to a $230 \mathrm{kV}$ external transmission network through a transformer and two parallel lines. System load (connected to Bus 18 in Fig. 2) is represented by static exponential constant power load model, without taking into account load dependency on system frequency.

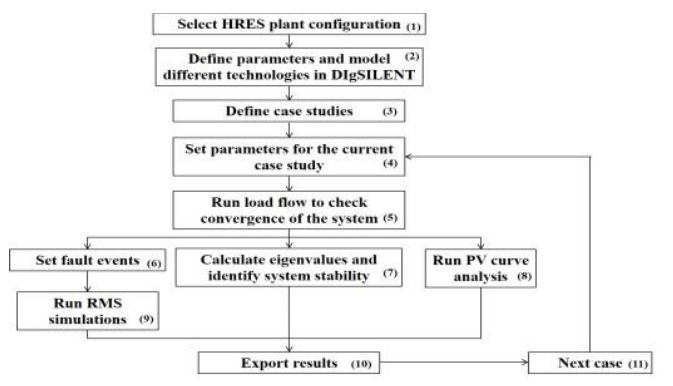

Fig. 1. The flow chart of the methodology.



Fig. 2. The schematic diagram of the test system (G: generation technology; S: storage technology).

The nominal power of all individual plants in the HRES plant is the same, 210 MVA. Unlike synchronous machine (SM)-based systems, the PV plant, WF, BESS and FESS are represented by a number of individual, identical, units connected in parallel (the nominal capacities of individual units are given in Table I). In the case of the PV plant and WF, the number of parallel units in operation is determined by the $\mathrm{PV}$ and WF power output, as it is assumed that units in service always operate at rated power output. On the other hand, the number of parallel units in operation in the BESS and FESS is constant but their power output depends on the operating point of the storage system (all units have the same power output).

As the WF consists of doubly-fed induction generators (DFIGs), a generic type 3 model, suitable for large system stability studies, is used for modelling WF individual units. The structure of the model is in line with the recommendations given by WECC [10] and IEC [11] and is available in DIgSILENT PowerFactory [9]. Similarly, a type 4 wind generator model, suitable for converter-connected technologies, is used to represent PV individual units. Both PV plants and type 4 wind generators are connected to the grid through a full-connected converter. As converter can be considered to decouple dynamics of the source on the DC part from the rest of the power system, both technologies can be represented by the same model in system stability studies [12]. This is also suggested by the WECC Renewable Energy Modeling Task Force [13], which develops a PV model by slightly modifying the type 4 wind generator model. The PV dynamic model used in the paper has a similar structure to [10], [11] and is also available in DIgSILENT PowerFactory [9]. The hydro generator is represented by the standard fifth order SM model, whereas the sixth order model is used for the biomass power plant and the CAES [8]. The control systems of the SMs consist of the standard IEEE DC1A exciter and IEEEG1 governor.

A battery device is represented as a static voltage source equipped with the adequate control system [14], [15]. The voltage source model takes into account the battery state of charge and battery internal losses. The battery control system contains a frequency controller, active power-voltage 
controller, charge controller and relevant protection mechanisms [16]. When it comes to the modelling of the FESS, a DFIG is chosen for connecting the flywheel to power system and the flywheel is represented as an additional inertia coupled to the DFIG rotor [17]. The control system of the FESS is modelled as suggested in [17]. It consists of a reference active power controller, a machine side converter control which enables independent control of active and reactive power, and relevant protection mechanisms.

TABLE I. NOMINAL CAPACITIES OF INDIVIDUAL UNITS

\begin{tabular}{|c|c|c|c|c|}
\hline Technology & PV & WF & BESS & FESS \\
\hline $\begin{array}{c}\text { Nominal capacity } \\
\text { (MVA) }\end{array}$ & 2 & 2 & 26.25 & 4 \\
\hline
\end{tabular}

\section{Results AND Discussion}

The list of 24 representative CSs used in the analysis is given in Table II. The values in Table II represent contributions of individual technologies to the total HRES plant active power output and are given in percentages. All the cases were designed in such a way that the total HRES plant active power production was equal to $210 \mathrm{MW}$ at steady state. The analyzed operating conditions can be divided into 3 groups on the basis of the share of generation and storage technologies in the HRES plant power output:

- Cases 1-6: generation technologies provide the total HRES plant active power production.

- Cases 7-11: equal contribution of generation and storage technologies to the total HRES plant active power production.

- Cases 12-24: generation technologies produce a 50\% surplus in the HRES plant active power production (with respect to the desired $210 \mathrm{MW}$ ), and the excess is absorbed by storage technologies.

Zero percentage in Table II has different meaning for generation and storage devices. Namely, if the contribution of a generation technology to the HRES plant power output is $0 \%$, the technology has to be disconnected from the grid. On the other hand, in the case of a storage system, its power output at steady state is set at $0 \mathrm{MW}$ and the technology remains connected to the network.

\section{A. Small Signal Stability}

As afore-mentioned, only electromechanical oscillation modes are used for the analysis of the impact of the HRES plant on small disturbance system stability. They were identified on the basis of mode frequency and participation factors [8]. The damping $(\sigma)$ and frequency $(f)$ of all electromechanical modes are given in Table III. As the CAES is always in service (even with zero power output at steady state), and the external network (see Fig. 2) is modelled as a large SM, the minimum number of electromechanical modes per CS is equal to one.

All 24 analyzed HRES plant compositions can be divided into 3 groups based on small signal stability results (the groups are marked by appropriate colors and letters in Table III), meaning that only 3 models are required for representing these operating points in small signal stability studies. Each group consists of CSs characterized by the same number of electromechanical modes (i.e., the same number of SMs in service) and similar damping and frequency of the electromechanical modes. Group A consists of the CSs with one electromechanical mode, i.e., the cases with a single SM in operation (the CAES). The second group, group B, includes the HRES plant compositions with 2 SMs in service, the hydro generator and the CAES. Finally, the third group contains the CSs with all $3 \mathrm{SMs}$ in operation. As can be seen from Table III, the damping and frequency of electromechanical modes associated with the CAES operation are the highest (on average, -1.17 and $1.33 \mathrm{~Hz}$, respectively), while the hydro power plant produces the least damped and the slowest electromechanical modes (on average, -0.67 and $1.07 \mathrm{~Hz}$, respectively). The frequency of all electromechanical modes is within the range of interplant mode oscillations [8].

TABLE II. LIST OF CASE STUDIES

\begin{tabular}{|c|c|c|c|c|c|c|c|}
\hline CS & PV & WF & Hydro & Biomass & BESS & FESS & CAES \\
\hline 1 & 25 & 25 & 25 & 25 & 0 & 0 & 0 \\
\hline 2 & 50 & 50 & 0 & 0 & 0 & 0 & 0 \\
\hline 3 & 0 & 0 & 50 & 50 & 0 & 0 & 0 \\
\hline 4 & 70 & 10 & 10 & 10 & 0 & 0 & 0 \\
\hline 5 & 10 & 70 & 10 & 10 & 0 & 0 & 0 \\
\hline 6 & 10 & 10 & 10 & 70 & 0 & 0 & 0 \\
\hline 7 & 0 & 0 & 25 & 25 & 35 & 0 & 15 \\
\hline 8 & 0 & 0 & 25 & 25 & 15 & 0 & 35 \\
\hline 9 & 0 & 40 & 5 & 5 & 35 & 0 & 15 \\
\hline 10 & 0 & 40 & 5 & 5 & 15 & 0 & 35 \\
\hline 11 & 5 & 5 & 20 & 20 & 15 & 0 & 35 \\
\hline 12 & 50 & 50 & 50 & 0 & -40 & -5 & -5 \\
\hline 13 & 50 & 50 & 50 & 0 & -5 & -40 & -5 \\
\hline 14 & 100 & 25 & 25 & 0 & -40 & -5 & -5 \\
\hline 15 & 100 & 25 & 25 & 0 & -5 & -40 & -5 \\
\hline 16 & 25 & 100 & 25 & 0 & -40 & -5 & -5 \\
\hline 17 & 25 & 100 & 25 & 0 & -5 & -40 & -5 \\
\hline 18 & 75 & 75 & 0 & 0 & -40 & -5 & -5 \\
\hline 19 & 75 & 75 & 0 & 0 & -5 & -40 & -5 \\
\hline 20 & 0 & 75 & 75 & 0 & -40 & -5 & -5 \\
\hline 21 & 0 & 75 & 75 & 0 & -5 & -40 & -5 \\
\hline 22 & 75 & 0 & 75 & 0 & -40 & -5 & -5 \\
\hline 23 & 75 & 0 & 75 & 0 & -5 & -40 & -5 \\
\hline 24 & 15 & 100 & 15 & 20 & -5 & -40 & -5 \\
\hline
\end{tabular}

\section{B. Transient Stability}

Three-phase self-clearing fault at Bus 19 (see Fig. 2) was selected as an external system disturbance. The fault occurs at $1 \mathrm{~s}$ and lasts for $100 \mathrm{~ms}$. Active and reactive power responses at the PCC were recorded for a period of 9 seconds after the fault clearing with a sampling rate of $10 \mathrm{~ms}$. Power responses are divided into groups according to similarity in shape; active and reactive power responses are observed separately.

Taking into account the frequency, damping and the first overshoot of the responses after the fault clearing, 24 active power transient responses can be divided into 4 groups, which are presented in Fig. 3 and Fig. 4. Grouping is mainly 
determined by the total power output of SMs and their individual production levels.

TABLE III. LIST OF ELECTROMECHANICAL MODES

\begin{tabular}{|c|c|c|c|c|c|c|c|}
\hline $\mathbf{C S}$ & $\begin{array}{c}\boldsymbol{\sigma}_{\mathbf{1}} \\
(\mathbf{1} / \mathbf{s})\end{array}$ & $\begin{array}{c}\boldsymbol{f}_{\mathbf{1}} \\
(\mathbf{H z})\end{array}$ & $\begin{array}{c}\boldsymbol{\sigma}_{\mathbf{2}} \\
(\mathbf{1 / s})\end{array}$ & $\begin{array}{c}\boldsymbol{f}_{\mathbf{2}} \\
(\mathbf{H z})\end{array}$ & $\begin{array}{c}\boldsymbol{\sigma}_{\mathbf{3}} \\
(\mathbf{1} / \mathbf{s})\end{array}$ & $\begin{array}{c}\boldsymbol{f}_{\mathbf{3}} \\
(\mathbf{H z})\end{array}$ & Group \\
\hline 1 & -0.84 & 1.14 & -0.67 & 1.05 & -1.20 & 1.32 & $\mathrm{C}$ \\
\hline 2 & - & - & - & - & -1.15 & 1.32 & $\mathrm{~A}$ \\
\hline 3 & -0.84 & 1.27 & -0.66 & 1.09 & -1.17 & 1.33 & $\mathrm{C}$ \\
\hline 4 & -0.83 & 1.08 & -0.68 & 1.03 & -1.20 & 1.32 & $\mathrm{C}$ \\
\hline 5 & -0.83 & 1.08 & -0.68 & 1.03 & -1.19 & 1.32 & $\mathrm{C}$ \\
\hline 6 & -0.88 & 1.35 & -0.67 & 1.03 & -1.09 & 1.31 & $\mathrm{C}$ \\
\hline 7 & -0.84 & 1.14 & -0.68 & 1.04 & -1.18 & 1.33 & $\mathrm{C}$ \\
\hline 8 & -0.84 & 1.14 & -0.67 & 1.04 & -1.06 & 1.36 & $\mathrm{C}$ \\
\hline 9 & -0.82 & 1.07 & -0.68 & 1.02 & -1.18 & 1.33 & $\mathrm{C}$ \\
\hline 10 & -0.82 & 1.07 & -0.68 & 1.02 & -1.06 & 1.36 & $\mathrm{C}$ \\
\hline 11 & -0.84 & 1.12 & -0.68 & 1.04 & -1.06 & 1.36 & $\mathrm{C}$ \\
\hline 12 & - & - & -0.66 & 1.10 & -1.21 & 1.32 & $\mathrm{~B}$ \\
\hline 13 & - & - & -0.66 & 1.10 & -1.21 & 1.32 & B \\
\hline 14 & - & - & -0.67 & 1.06 & -1.21 & 1.32 & B \\
\hline 15 & - & - & -0.67 & 1.06 & -1.21 & 1.32 & B \\
\hline 16 & - & - & -0.67 & 1.06 & -1.20 & 1.32 & B \\
\hline 17 & - & - & -0.67 & 1.07 & -1.20 & 1.32 & B \\
\hline 18 & - & - & - & - & -1.18 & 1.32 & A \\
\hline 19 & - & - & - & - & -1.17 & 1.32 & A \\
\hline 20 & - & - & -0.63 & 1.14 & -1.20 & 1.32 & B \\
\hline 21 & - & - & -0.63 & 1.14 & -1.20 & 1.32 & B \\
\hline 22 & - & - & -0.63 & 1.14 & -1.21 & 1.32 & B \\
\hline 23 & - & - & -0.63 & 1.14 & -1.21 & 1.32 & B \\
\hline 24 & -0.83 & 1.12 & -0.67 & 1.04 & -1.22 & 1.32 & C \\
\hline
\end{tabular}

The first group includes CSs dominated by converter-connected technologies (CSs: 2, 4, 5, 9, 10, 14-19, 24). Their active power responses are characterized by short settling time and insignificant oscillatory behavior. The system stabilizes within approximately 3 seconds after the fault occurrence. The aggregated contribution of SMs to the HRES plant active power production in pre-fault state, as well as their individual production, is below or equal to $30 \%$. The only exception is CS 10 in which SMs produce about a half of the total plant output, but their individual production is low (see Table II). Group 2 (CSs: 1, 7, 8, 11-13) contains operating conditions characterized by SMs providing (45-85) \% of the total HRES plant active power output. The maximum SM production per case is between $25 \%$ and $50 \%$ of the nominal capacity. The frequency of the responses is around $1.1 \mathrm{~Hz}$, while it takes about 5 seconds for the responses to stabilize.

The third group (CSs: 3, 20-23) includes cases with the total contribution from SMs of $70 \%$ and above and the dominant production from the hydro power plant. Generation level of the hydro generator is $75 \%$ of the nominal capacity, expect in case 3 characterized by the hydro and biomass power plants having equal generation of $50 \%$ of the nominal capacity. In addition, CS 3 is the only case in this group with the biomass generator in service. The frequency of the responses is slightly higher than in the case of group $2-$ $1.2 \mathrm{~Hz}$, and the responses stabilize around 4 seconds after fault occurrence. Finally, group 4 contains a single HRES plant composition, CS 6 , which is described by the $80 \%$ of the total plant power output coming from the hydro and biomass generators. Unlike the compositions assigned to group 3 , the biomass generator has the largest share in HRES plant production in this CS. Biomass power plant response is characterized by the largest frequency among the responses of all considered SMs - around 1.5 Hz. Damping of this response is similar to the damping of the responses from group 3 .

When it comes to reactive power responses, three levels of reactive power at steady state can be defined. The levels are determined by the number of SMs in service as they are the main providers of reactive power. The only exception is case 24 (all 3 SMs in operation) which results in reactive power level more similar to the cases with $2 \mathrm{SMs}$ in service. The reason for this is a large number of connected DFIG units - the WF generates $210 \mathrm{MW}$ in this operating scenario. As seen in Fig. 5, all reactive power responses are characterized by identical shape, meaning that the individual production levels of SMs have smaller impact on the characteristics of reactive power responses compared to active power responses.

\section{Voltage Stability}

The system presented in Fig. 2 is not suitable for carrying out voltage stability studies due to low system loading and large external network capacity. Thus, in order to obtain more realistic results, the system was slightly modified by connecting additional loads to Bus 19 (370 MW) and Bus 20 (250 MW) and extending the length of the line that connects the external grid to the HRES plant from $1 \mathrm{~km}$ to $70 \mathrm{~km}$. Voltage stability analysis was performed by increasing only the load connected to Bus 18 (see Fig. 2) which consumes $21 \mathrm{MW}$ at initial steady state.

Three distinct patterns, in terms of load margin and critical bus voltage magnitude, are identified in voltage stability studies for the analyzed operating points. As in the case of small signal stability and reactive power transient responses, the number of SMs in service defines the grouping. Individual generation levels of SMs do not influence voltage stability grouping. The load margin and critical bus voltage magnitude are shown in Fig. 6 for the considered operating scenarios. As expected, the lowest load margin (around $20 \mathrm{MW}$ ) occurs in the cases dominated by converter-connected technologies, while technology mixes with all SMs in service can withstand the largest increase in the system load (load margin is about $180 \mathrm{MW})$.
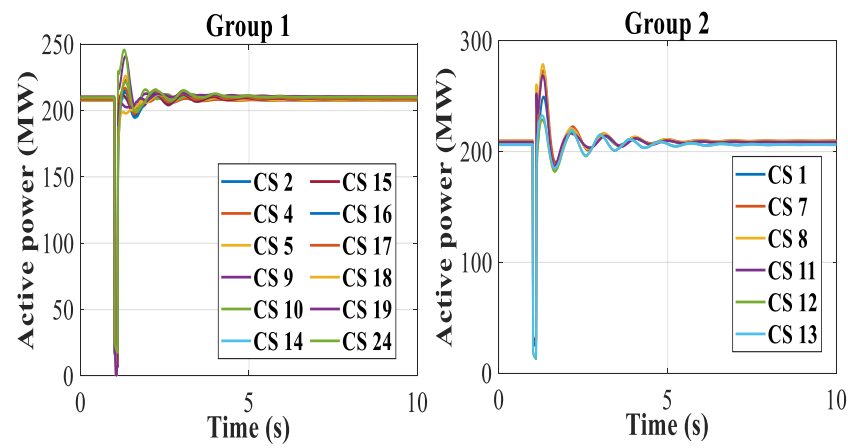

Fig. 3. Active power transient responses: Group 1(left) and Group 2 (right). 

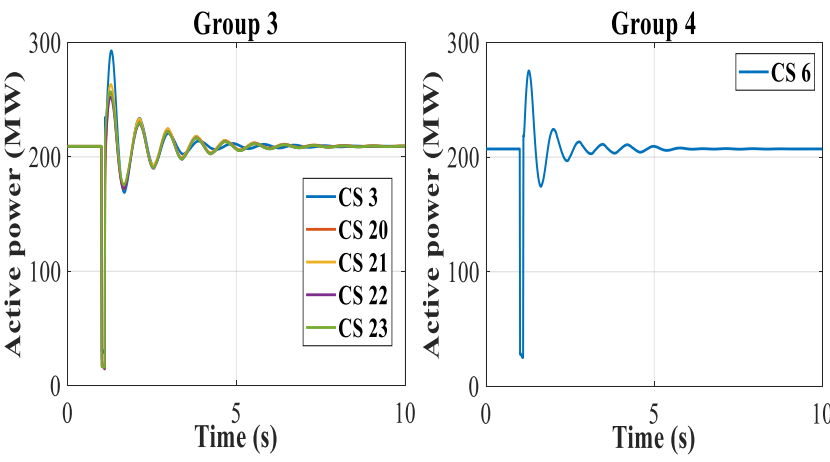

Fig. 4. Active power transient responses: Group 3(left) and Group 4 (right).

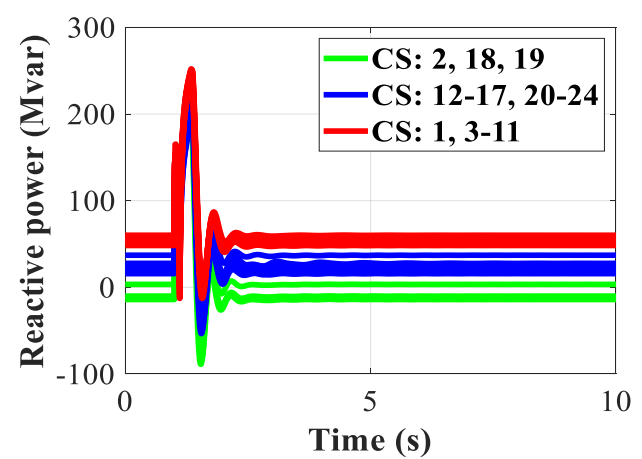

Fig. 5. Grouping of reactive power transient responses.



Fig. 6. Voltage stability grouping.

\section{CONCLUSION}

The paper has presented the analysis of the impact of the HRES plant on small signal, transient and voltage transmission system stability. The test power plant consists of non-dispatchable and dispatchable RES technologies along with storage systems, all connected to a single PCC.

The HRES plant responses in all three types of system stability studies are mainly determined by the number of SMs in service and their individual production. It has been shown that the same three groups of HRES plant compositions are characterized by similar HRES plant behavior in the case of small disturbance and voltage stability and reactive power transient responses. On the other hand, four distinct patterns are identified in active power transient responses at the PCC. Grouping of HRES plant compositions in this case is less influenced by the number of SMs in service compared to the remaining stability analyses.

Results obtained with the test system have demonstrated that the behavior of the whole HRES plant can be represented by few models in any of the considered system stability studies, and thus, have laid a foundation for developing small number of dynamic equivalents of the HRES plant that can be used throughout the year in system dynamic studies. This would result in more efficient dynamic simulations and significantly reduced modelling effort as these models could be developed once and stored in dedicated software library and then used throughout the year depending on relevant HRES plant composition.

\section{ACKNOWLEDGMENT AND DISCLAIMER}

The research is supported by the EU H2020 project CROSSBOW (grant agreement 773430). The paper reflects only the authors' views and neither the Agency nor the Commission are responsible for any use that may be made of the information contained therein.

\section{REFERENCES}

[1] IEA-PVPS, "Flexible resources for flexible transmission system operation," IEA-PVPS Task 14: "High Penetration of PV Systems in Electricity Grids," Subtask 3: "High penetration solutions for central PV generation scenarios," IEA INTERNATIONAL ENERGY AGENCY, T14-09:2017, October 2017.

[2] T. Ackermann, G. Andersson, and L. Söder, "Distributed generation: a definition,” Elec. Pow. Syst. Res., vol. 57, no. 3, pp. 195-204, April 2001.

[3] R. A. Walling, R. Saint, R. C. Dugan, J. Burke, and L. A. Kojovic, "Summary of Distributed Resources Impact on Power Delivery Systems," IEEE Trans. Power Del., vol. 23, no. 3, pp. 1636-1644, June 2008

[4] A. M. Azmy, I. Erlich, "Impact of distributed generation on the stability of electrical power system," presented at the IEEE Power Engineering Society General Meeting, San Francisco, CA, USA, June, 2005.

[5] M. K. Deshmukh and S. S. Deshmukh, "Modeling of hybrid renewable energy systems,” Renew. Sustain. Energy Rev., vol. 12, no. 1, pp. 235249, January 2008.

[6] P. K. Olulope, K. A. Folly, and G. K. Venayagamoorthy, "Modelling and simulation of hybrid distributed generation and its impact on transient stability of power system," in Proc. 2013 IEEE International Conference on Industrial Technology (ICIT), pp. 1757-1762, Cape Town, South Africa, February 2013.

[7] S. M. Zali, and J. V. Milanović, "Generic model of active distribution network for large power system stability studies,” IEEE Trans. Power Syst., vol. 28, pp. 3126-3133, August 2013.

[8] P. Kundur, Power system stability and control. McGraw-Hill, 1994.

[9] DIgSILENT-PowerFactory User Manual v15, DIgSILENT GmbH, 2014.

[10] WECC Wind Power Plant Dynamic Modeling Guide, WECC Renewable Energy Modeling task Force, January 2014.

[11] Wind turbines - Part 27 - 1: Electrical simulation models - Wind turbines, IEC 61400-27-1, 2015.

[12] P. N. Papadopoulos, J .V. Milanovic, "Probabilistic framework for transient stability assessment of power systems with high penetration of renewable generation", IEEE Trans. Power Syst., vol. 32, no. 4, pp. 3078-3088.

[13] WECC PV Power Plant Dynamic Modeling Guide, WECC Renewable Energy Modeling Task Force, May 2014.

[14] A. Adrees, H. Andami, J. V. Milanović, "Comparison of dynamic models of battery energy storage for frequency regulation in power system," in 18th Mediterranean Electrotechnical Conference, MELECON 2016, Limassol, Cyprus, April 2016.

[15] A. Kanchanaharuthai, V. Chankong, and K. A. Loparo, "Transient Stability and Voltage Regulation in Multimachine Power Systems Visà-Vis STATCOM and Battery Energy Storage," IEEE Trans. Power Syst., vol. 30, no. 5, pp. 2404-2416, September 2015.

[16] A. Adrees, and J.V. Milanović, "Impact of energy storage systems on the stability of low inertia power systems," in 2017 IEEE PES Innovative Smart Grid Technologies Conference Europe (ISGTEurope), Torino, Italy, September 2017.

[17] A. Adrees, J. Song, and J.V. Milanović, "The influence of different storage technologies on large power system frequency response," 2016 IEEE 8th International Power Electronics and Motion Control Conference (IPEMC-ECCE Asia), Hefei, China, May 2016. 